\title{
Hospital survival associated with the use of thromboprophylaxis in patients with severe COVID-19 infection
}

\author{
Víctor M. Camarillo Nava ${ }^{1}$, José Vicente Rosas ${ }^{2}$, José A. Zamudio González ${ }^{1}$, Jorge Luis \\ Zendejas Villanueva ${ }^{1}$, Elizabeth López Rojas ${ }^{1}$, Norma A. Hernández Pineda ${ }^{1}$, and José \\ Andrade Pineda ${ }^{1}$ \\ ${ }^{1}$ Instituto Mexicano del Seguro Social \\ ${ }^{2}$ Instituto de Seguridad y Servicios Sociales de los Trabajadores del Estado
}

January 17, 2021

\begin{abstract}
Hospital survival associated with the use of thromboprophylaxis in patients with severe COVID-19 infection Survival and thromboprophylaxis in COVID-19 Abstract Introduction: It has been described that patients with severe or critical infection by COVID-19 suffer an inflammatory state that conditions a high thrombotic risk. However, there is little information on how to address thrombotic risk, coagulopathy, and anticoagulant therapy in these patients. Objective: To evaluate the use of thromboprophylaxis in patients with severe COVID-19 infection associated with longer survival. Material and methods: Retrospective cohort study, in a 2nd level hospital. 340 records of patients hospitalized for severe COVID-19 infection were reviewed, and 171 were included in the final analysis. Sociodemographic data, previous pathologies, days of hospital stay, respiratory parameters were evaluated; blood gas, hematic cytometry, DHL, C-reactive protein (CRP), antiviral treatment, thromboprophylaxis, use of steroids and use of antibiotics, the study variable was survival associated with the use of LMWH. Descriptive, inferential statistics, univariate and multiple models were used. Results: Advanced age, $\mathrm{PaO} 2$ / FiO2 index $>200$ and high CRP were associated with a higher probability of death. And the greater the number of days of use of thromboprophylaxis; the higher the degree of protection. The PaO2 / FiO2 index > 200 (adjusted HR 0.270; 95\%CI;. 0.100-0.727) and greater number of days with thromboprophylaxis (adjusted HR, 0.576; 95\%CI;. $0.460-0.721$ ) during hospitalization, were factors associated with hospital survival. Conclusions: In this study we found evidence to recommend the use of thromboprophylaxis from the first hours of admission in adult patients with severe COVID-19 as long as there are no contraindications for it, due to the increase in hospital survival. KEY WORDS: Thromboprophylaxis, LMWH, SARS-CoV-2, survival, Severe COVID-19 infection.
\end{abstract}

\section{Hosted file}

Hospital survival associated with the use of thromboprophylaxis in patients with severe COVID-19 infect available at https://authorea.com/users/389944/articles/504433-hospital-survival-associatedwith-the-use-of-thromboprophylaxis-in-patients-with-severe-covid-19-infection

\section{Hosted file}

Tables.pdf available at https://authorea.com/users/389944/articles/504433-hospital-survivalassociated-with-the-use-of-thromboprophylaxis-in-patients-with-severe-covid-19-infection

\section{Hosted file}

Figuras 4.pdf available at https://authorea.com/users/389944/articles/504433-hospitalsurvival-associated-with-the-use-of-thromboprophylaxis-in-patients-with-severe-covid-19infection 